\title{
AMENDMENTS
}

\section{Author Correction: Hitchhiking into the cell}

Douglas B. Kell(1)

Correction to: Nature Chemical Biology https://doi.org/10.1038/s41589-020-0489-x, published online 9 March 2020.

In the version of this News and Views originally published, the figure title incorrectly stated 'drug transporter' and the first sentence of the legend was ambiguous. The first sentence of the legend for Fig. 1 should state "Real biomembranes in cells have protein:phospholipid ratios (by mass) that are well in excess of one, and this minimizes any bilayer transport of small molecules" and the title should read "Solute carriers are required for drug transport across cellular membranes." The errors have been corrected in the HTML and PDF versions of the paper.

Published online: 8 April 2020

https://doi.org/10.1038/s41589-020-0540-y

() Springer Nature America, Inc. 2020

\section{Author Correction: Plasma membranes are asymmetric in lipid unsaturation, packing and protein shape}

\author{
J. H. Lorent (D), K. R. Levental DD, L. Ganesan, G. Rivera-Longsworth, E. Sezgin (D), M. Doktorova, E. Lyman and I. Levental (D)
}

Correction to: Nature Chemical Biology https://doi.org/10.1038/s41589-020-0529-6, published online 4 May 2020

In the version of this article originally published, the name of co-author M. Doktorova was incorrectly presented as 'M. D. Doktorova' in the author list and in the author contributions section (as 'M.D.D.'). The errors have been corrected in the HTML and PDF versions of the paper.

Published online: 15 May 2020

https://doi.org/10.1038/s41589-020-0564-3

(c) The Author(s), under exclusive licence to Springer Nature America, Inc. 2020 